\#WORK! THE EFFECT OF HASHTAG CAMPAIGNS:

A MODERN FORM OF FREE LABOUR

by

Nadine Yacoub

BA, University of Ottawa, 2015

\author{
A MRP \\ presented to Ryerson University \\ in partial fulfillment of the \\ requirements for the degree of \\ Master of Professional Communication \\ In the Program of \\ Professional Communication
}

Toronto, Ontario, Canada, 2017

C) Nadine Yacoub, 2017 


\section{Author's Declaration for Electronic Submission of a MRP}

I hereby declare that I am the sole author of this MRP. This is a true copy of the MRP, including any required final revisions.

I authorize Ryerson University to lend this MRP to other institutions or individuals for the purpose of scholarly research.

I further authorize Ryerson University to reproduce this MRP by photocopying or by other means, in total or in part, at the request of other institutions or individuals for the purpose of scholarly research.

I understand that my MRP may be made electronically available to the public. 


\title{
THE EFFECT OF HASHTAG CAMPAIGNS: A MODERN FORM OF FREE LABOUR
}

\author{
Nadine Yacoub \\ Master of Professional Communication \\ Ryerson University, 2017
}

\begin{abstract}
This MRP will attempt to explain social media today by applying Smythe's (2006) research on audience commodity and free labour regarding television and broadcast to hashtag campaigns on Instagram, such as Coca-Cola's \#ShareaCoke, and Calvin Klein's \#MyCalvins. This MRP will support literature pertaining to audience commodity and free labour, the monetization of usergenerated content via social media marketing, and the nature of the audience. Through a mixed methods approach, the campaigns will be analyzed in hopes of discovering how social media has revolutionized the role of the audience, which has shifted drastically due to the participatory nature of the Internet - thus, demonstrating the transformation of the audience as users to producers to advertisers of user-generated content created for hashtag campaigns on Instagram. Ultimately, this MRP will seek to demonstrate that this transformation has resulted in exploitation of users, and have revolutionized the model of free labour and commodity as outline by Smythe (2006).
\end{abstract}




\section{Acknowledgements}

I would like to thank Dr. Greg Elmer for all his support, guidance and patience throughout my research and MRP process. I would also like to thank my second reader, Dr. John Shiga, for his valuable input and expertise in the subject matter. 


\section{Table of Contents}

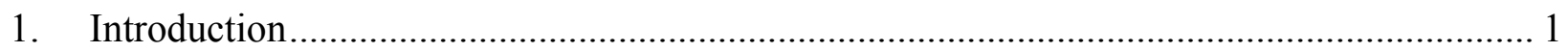

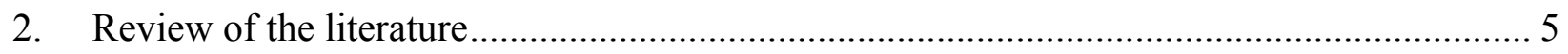

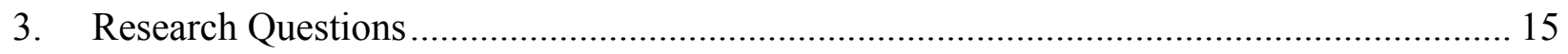

4. Data Collection Approach and Method of Analysis ................................................. 18

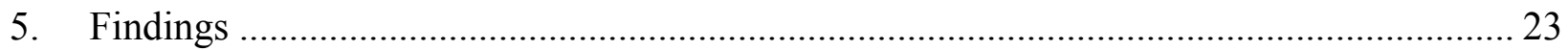

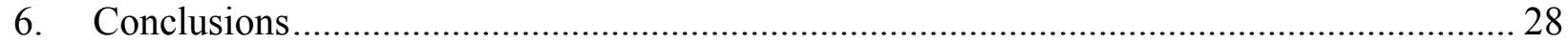

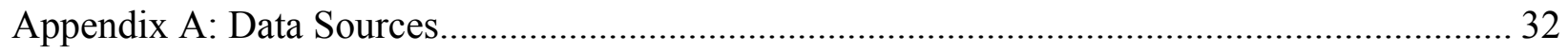

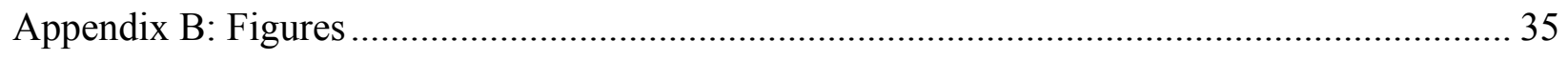

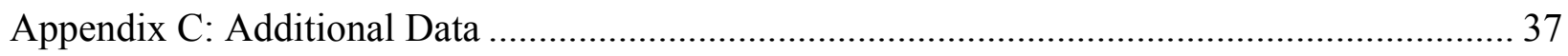

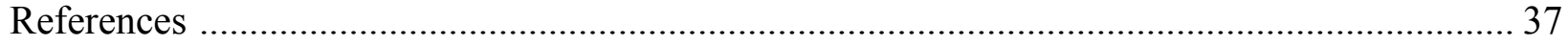




\section{Introduction}

The topics I wish to explore for my MRP are the notions of audience commodity and free labour in today's digital age, particularly through the use of the hashtag (\#) on Instagram and its implications in relation to user-generated content.

These concepts were originally introduced by Smythe (2006), who specialized in the study of television broadcast. The area of his research concentrated on "the principal product of the commercial mass media in monopoly capitalism" which he believed to be audience power (Smythe, 2006). Smythe described this notion as a commodity due to its ability to be "produced, sold, purchased and consumed" (Smythe 2006, p. 198). In other words, audience power retains a price, and is therefore considered "a concrete product used to accomplish economic and political tasks" (Smythe, 2006, p.198), which subsequently renders the audience as a tool for institutions and organizations. Due to the emergence of the digital age, there has been a decline in the effectiveness of television advertising as more and more audiences shift to the Internet (Eastin, Daugherty, Burns 2011). Thus, as a result, advertisers are simply following the audience to their latest platform - Instagram. Instagram is a social networking application used to share multimedia, such as photos and videos via mobile phone with one's social circle. Since Smythe's (2006) research mainly focused on television broadcast, the goal of this MRP will be to determine the implications of Smythe's theory of audience commodity and free labour in relation to Instagram, which is being used as a space for free labour by promoting products and, "producing culture for the digital economy" (Terranova, 2000).

Throughout this MRP, I will seek to portray how social media has revolutionized the role of the audience, which has shifted drastically due to the participatory nature of the Internet (Livingstone, 2017; Napoli, 2016). I hope to demonstrate the transformation of the audience as 
producers/advertisers of content through the use of user-generated content on social networking websites (see Livingstone, 2017; Napoli 2016). My research will focus on hashtag campaigns on Instagram such as Calvin Klein's \#MyCalvins and Coca Cola's \#ShareaCoke which were implemented back in 2014. Although not a novelty, I have chosen these two reputable brands due to the success and recognition they have received over time regarding their social media campaigns.

The purpose of Coca-Cola's campaign was to personalize their brand with their consumers (Hepburn, n.d.). Thus, they modified the packaging on their bottles by removing their logo and replacing it with some of the UK's most popular names in hopes of giving its consumers a chance to create special moment by sharing a personalized Coke with their friends and family (See figure 1.1) (Hepburn, n.d). Coca-Cola then invited its consumers to share their purchases online by using the \#ShareaCoke hashtag - thus creating an endless stream of usergenerated content. In fact, throughout 2014, the Share a Coke campaign generated 998 million impressions on Twitter, 235,000 tweets from 111,000 fans using the hashtag \#ShareaCoke, and more than 150 million personalized bottles sold (Hepburn, n.d.). ${ }^{1}$ As a result of its success, the campaign has been launched in more than 70 countries and received seven awards during the 2012 Cannes Lions Festival, a celebration of creative communications, entertainment, and design (Hepburn, n.d.). Although the Share a Coke campaign was mostly propagated on Twitter, this MRP will seek to demonstrate its current progress on Instagram.

Regarding Calvin Klein, the \#MyCalvins campaign has also achieved success, but through celebrity endorsement and influencer marketing, which indicates a paid endorsement

\footnotetext{
${ }^{1}$ Impressions are the number of times a post from your page is displayed elsewhere.
} 
between both the brand and its collaborating partners. In 2014, they launched their campaign by sharing a photo on Instagram inviting users to "Show [their Calvin's"] (see figure 1.2). The goal of the campaign was to attract consumers into purchasing Calvin Klein underwear and share them on social media with their social circle. Within four months of its launch, 4.5 million interactions between celebrity, influencers, and brand-posted content was generated on Instagram (Leo, 2016). Since the launch in 2014, their social media channels have seen a significant growth with an increase of 2.2 million followers on Facebook, 1.8 million followers on Instagram, and 1 million followers on twitter. (Leo, 2016).

Despite a difference in strategy, both these campaigns relied heavily on user-generated content to promote a product or a brand with the intentions of maximizing coverage via social media hashtag campaigns. According to the Organization for Economic Co-operation and Development (OECD, 2007) when discussing the "participative web", UGC is defined as content published via the online public domain, which demonstrates "a certain amount of creative effort [...] created outside of professional routines and practices (p. 9). In other words, for content to be considered user-generated, it must be published, requires creative efforts, and does not have commercial market factor (OECD, 2007). On Instagram, users utilize the hashtag to identify the theme, context, or topic of their user-generated content (Laestadius \& Wahl, 2007). Subsequently, marketers also generate their own hashtags and employ them in print and online advertising, as well as packaging, with the intentions of activating consumers to post and in directly promote their brand (Laestadius \& Wahl, 2007). Through such campaigns, organizations ultimately seek to access more audiences — thus, the audience becomes a commodity (Smythe, 2006; Fuchs, 2012). To access more audiences, organizations entice users to participate in their campaign by generating more content through the implementation of the hashtag. With such a 
strategy, the audience now becomes producers of content via the content they create (see Livingstone, 2007; Napoli, 2016). As producers of content, they subsequently perform a form of free labour for these organizations by generating value through the information they share via their social network (Andrejevic, 2002; Terranova, 2007).

Through such developments, I hope to demonstrate the transformation of the audience as producers to advertisers of content by analyzing various hashtag campaigns using user-generated content on social networking websites. Ultimately, this MRP will attempt to examine the different types of marketing strategies on Instagram utilized by organizations that employ "the hashtag" as a device to advertise a brand by enticing the audience to implement its propagation through user-generated content which ultimately leads to the commodification of the audience and their exploitation. Thus, this MRP will seek to determine:

1. How does Smythe's (2006) work regarding free labour in relation to television and broadcast help us understand social media today?

2. How do online brands, such as Coca-Cola and Calvin Klein, encourage or activate the audience to participate in online campaigns?

3. Are users supportive of the campaign?

To answer these research questions, this MRP will review literature on audience commodity and free labour, the monetization of user-generated content, the role shift of the audience, and marketing on social media. This MRP will attempt to apply literature to both quantitative and qualitative data collected via content analysis. Methods regarding data collection are further throughout this text. 


\section{Review of the literature}

This research paper will review literature pertaining to three integral elements, such as the theory of audience commodity and free labour, marketing on social media via user-generated content (UGC), and lastly, the nature of the audience. The first review will seek to understand the notion of free labour, particularly regarding its implications within the digital economy to better understand its relation to user-generated content and the audience. The second review will focus on user-generated content and its monetization and commodification within social networking websites. The third review will focus on the nature of the so-called audience, and its transformation from user to producer and advertiser.

\subsection{Audience Commodity and Free Labour}

The purpose of this research paper is to discover whether the audience is engaging in a form of free labour when propagating data through UGC on Instagram by participating in hashtag campaigns implemented by various brands. In order to further expand on the notion of free labour, its history and evolution will be analyzed in order to demonstrate its significance to this research. The first mention of this concept was introduced by Smythe (2006) while trying to differentiate between the division of material and intellectual labour. Usually, any form of labour requires an individual to perform some form of work, which subsequently results in monetary compensation (Smythe, 2006). However, while studying television broadcast, Smythe (2006) suggested that the audience was working for free by watching. Consequently, the audience then becomes a product for the commercial mass media, which ultimately leads to their commodification (Smythe, 2006). Throughout his works, Smythe (2006) believed audience power to be "the principal product of the commercial mass media in monopoly capitalism". Audience power is consistent with the elements of what constitutes a commodity, since it can be 
"produced, sold, purchased, and consumed" (Smythe, 2006, p. 198). Due to such, audience power possesses a price, and is therefore considered "a concrete product used to accomplish economic and political tasks," (Smythe, 2006, p.198) which ultimately renders the audience as a tool for institutions and organizations. Due to the value generated by audience power, it becomes a commodity (Smythe, 2006). According to Smythe, an "exchange value" occurs between the media and its consumption from its audience (Durham \& Kellner, 2006). He introduces the notion of "free labour", which implicates the audience in a form of unpaid work by watching for advertising companies (Durham \& Kellner, 2006). Since then, the definition of free labour has been revisited, expanded and redefined. Further building on Smythe's (2006) theory, Jhally and Livant (1986) maintain that same idea, however, they also suggest that the audience is "watching extra" by taking part in the interpretive aspects of watching, such as deciphering advertisements. Due to such, the media intends to maximize the commodity of surplus of watching (watching extra) by incorporating more advertising time to programs, which forces the audience to engage in supplementary work (Jhally \& Livant, 1986). However, Jhally and Livant (1986) insist that the wage audiences receive in exchange for watching is the television program itself. In other words, the audience watches "extra" by watching advertising programs in exchange for nonadvertising programs such television shows (Fuchs, 2012; Jhally \& Livant, 1984). However, Fuchs (2012) challenges Jhally's premise by stating that "wage" must correspond to a society built on money and capital for it to be legitimate. Audiences cannot convert the wage they receive by watching television programs, and subsequently cannot sustain a lifestyle by watching television. Therefore, it cannot be considered an admissible wage. (Fuchs, 2012). For that reason, all watching of commercial television is considered labour without pay (Fuchs, 2012). However, Fuchs (2012) applies Jhally and Livant's (1984) argument to targeted advertising on the Internet, 
which creates surplus value production for advertisers since they are reaching a larger targeted demographic. In relation to my research, this notion demonstrates the obscuring of boundaries between entertainment and advertising. Although Jhally and Livant (1984) mainly focused on television broadcast, their observations can be used to understand how entertainment and advertising not only intersect on social networking platforms, but are parallel and reciprocal concepts that coincide through user generated content.

In consideration of the foregoing, the "digital labour" debate surfaces and prompts many critiques regarding the constitution of "free labour" in the digital economy. Some have defined free labour as the work of being watched (Andrejevic, 2002). Andrejevic (2002) introduced the term "value generating-labour", which implies that there is value in the information generated online through online interactions due to comprehensive computer monitoring of user-generated content. This process occurs when users are enticed to expose the details of their lives online which creates informational content for marketers, such as viewing habits, shopping habits, and location monitoring (Andrejevic, 2002). It is important to keep in mind that Andrejevic's observations vastly redefine the constitutions of market research and how advertising works. Advertisers no longer need to spend large sums of money to gather consumer data, since it is now so readily available (Andrejevic, 2002). Although Andrejevic's findings focused on data collection regarding consumer behavior, the essence of his research can be applied to Instagram where data is being generated by users online while participating in hashtag campaigns.

Further expanding on the digital labour debate, some have insisted that social networking platforms, such as Facebook or Twitter, do not exploit its users since they provide a service in return (Fuchs, 2012). However, Fuchs (2012) argues that such Internet platforms provide a free communication service in exchange for the commodification of data which they use to monitor 
behaviour. This data is then tailored to the users and results in targeted advertising (Fuchs, 2012). Fuchs (2012) relates this concept back to his disagreement with Jhally (1984) where he insists that users are being exploited since there is no legitimate compensation for the data they provide. Having mere access to a communication service is not a method of survival and therefore cannot be considered a legitimate wage since "the relationship between users and platforms [is not] organized in the form of a modern wage relationship" (Fuchs, 2012, p. 703). In this case, users are double commodities, they work by providing data which in itself is a commodity, and in return they are being advertised to in a form of tailored advertising through the data they've provided, without any form of compensation (Fuchs, 2012). Relating back to this research paper, these observations can be applied to the ways in which hashtag campaigns collect data on their consumers via user-generated content. However, instead of targeted advertising, users are now doing the advertising by posting on behalf of the brand, and therefore advertising to their following. Ultimately, this research paper will seek to demonstrate how users are double commodities.

Terranova (2000) describes free labour as "the voluntary, unwaged, enjoyed, and exploited act of "building Web sites, modifying software packages, reading and participating in mailing lists, and building virtual spaces on MUDs and MOOs" (p.33). She bases her work on Lazzarato's (1996) research regarding skilled workers in the digital labour force who specialize in cybernetics and computer control. Considering the drastic shift regarding work processes, Lazzarato (1996) states that these workers perform a type of immaterial labour "which includes activities that do not fit within the traditional definition of work, but "produces the informational and cultural content of the commodity" (p. 132). He specifies that "informational" refers to the digital labour processes involved in industrial companies (Lazzarato, 1996). Furthermore, 
immaterial labour also includes activities that define cultural conventions, etiquette of fashion, consumer behaviour, and public opinion, which are all important aspects of any form of economy (Lazzarato, 1996). Based on such, Terranova (2000) suggests that the Internet accelerates the accumulation of productive networks of immaterial labour in a collective entity of knowledge which ultimately builds culture for the digital economy. In other words, Terranova (2007) implies that the act of producing content online corresponds to Smythe's (2006) notion of free labour, where users are working for free by producing and absorbing content. However, the content produced is intangible (immaterial), yet sustaining the digital economy. Essentially, Smythe (2006) and Terranova (2007) describe the same concept, but differ in how free labour is commodified. Pybus and Cote (2000) go a step further and apply this notion to Myspace, where consumption has turned into capital production. On Myspace, users are invited to connect to a multitude of online friends and browse each other's profile, as well as share information amongst each other. This information consists of preferences regarding music, television and desires (Pybus \& Cote, 2000). In return, Myspace capitalizes this valuable information about its consumers. Pybus and Cote (2000) relate back to Smythe's theory of audience commodity and suggest a new commodity, "Immaterial Labour 2.0", which is driving new revenue for the digital economy. Immaterial Labour 2.0 can be translated to user-generated content which includes any information shared regarding tastes, preferences, and social narratives among Internet peers (Pybus and Cote, 2000). In other words, websites are no longer obligated to produce entertainment, but expect users to flock and amass itself through the production of UGC, and the so-called culture mentioned throughout this text (Fuchs, 2010). For instance, companies such as Facebook depend on this content to survive as an entity considering it hosts strictly usergenerated content (Fuchs, 2010). Consequently, users create "culture", as defined by Lazarato 
(1996), on Facebook and consequently sustain the digital economy. Regarding this research paper, the notion of immaterial labour can be applied to Instagram, which is a photo sharing website, similar to Myspace in terms of sharing information and building a network of friends. It will be interesting to determine how brands and organizations use hashtag campaigns to create "culture" for the digital economy through immaterial labour, which then in return entices users to also do the same. In fact, Klein (2000) addresses how brands invade public space, such as the Internet, in order captivate attention among its consumers (Arvidsson, 2005). The following section of this literature review will further address the propagation of immaterial labour, such as UGC.

\subsection{Marketing on Social Media through UGC}

Since this research paper will be focusing on UCG via Instagram, this review will unpack literature regarding the nature of UGC on social media, sometimes called "immaterial labour", and its conversion into capital profit through marketing practices on social media.

As previously mentioned, the emergence of the digital age has prompted a decline in the effectiveness of television advertising as more and more audiences turn to the Internet (Eastin, Daugherty, Burns 2011). Although social media and traditional media share some characteristics, traditional media is limited because it seeks to attract attention within a confined space (McStay, 2010). However, social media allows for an endless possibility of web pages and hyperlinks permitting users to venture elsewhere (McStay, 2010). Subsequently, advertisers are simply following the audience to their latest platform--social networking sites. A social networking site can be described as an online resource that enables and facilitates the sharing of content, such as photos, videos, text and ideas among people (Drury, 2008). A common term to define the Internet's ability to amplify creativity and communication is called the "participative web" 
(OECD, 2007). As per Drury (2008), the 'social' component of social media is of crucial importance because it allows 'content' to become democratized when users share and interact with each other. Due to such, there has been a surge in research regarding the interactive nature of the Internet and UGC. Arvidsson (2008) defines UGC as productive communication which brands build on to create an ethical surplus which he defines as social bond or shared experience. In other words, marketing within social media becomes about building a relationship and engaging a brand with the online audience by providing content instead of a simple relatable message (Drury, 2008). To be specific, marketers seek consumer activation (Serazio, 2015).

Arvidsson (2008) calls attention to Holt's observation regarding "postmodern brand management. Holt (2000) suggests that a brand presents itself as a "cultural resource" to its consumers and then takes advantage of what consumers produce with such resource (Arvidsson, 2008). Holt's research on postmodern brand management can be applied to hashtag campaigns in which I wish to analyze. A hashtag campaign is an example of a "cultural resource" that presents itself as a part of the Internet culture, but depends on its consumers to produce content, in which they then capitalize. In technical terms, the hashtag simply acts as a hyperlink or portal directing users elsewhere by facilitating the online search of a topic, such as the \#MyCalvins and \#ShareaCoke campaigns. By simply clicking on the hashtag, the user is directed to a page with an abundance of user-generated content relating to that topic. That being said, technology and procedure for how content is delivered has shifted (McStay, 2010). In fact, marketers promote their own products directly on social media, but also seek to engage users to promote their products for them via personal user-generated content. (Laestadius and Wahl, 2017). According to Laestadius and Wahl (2017), this concept is called user-generated branded content, which is perceived as authentic among users, and consequently valuable for marketers. Laestadius and 
Wahl (2017) explain that the desire of creating user-generated content from users stems from "the enjoyment that they receive from contributing to a creative process and engaging in selfexpression, sharing opinions and information, interacting with their peers, or gaining some form of temporary celebrity status or prestige" (p.2). Referring to Smythe's theory of audience commodity, Fuchs (2010) suggests the interactive nature of the Internet commodifies human creativity due the abundance of knowledge that it fosters and produces while users communicate through UGC. Evidently, the relationship between free labour and UGC unite. There is no official explanation as to why the audience participates in such a phenomenon, however, Rohm, Kaltcheva, and Milne (2013) identify 10 motivations or themes that characterize brand-consumer interaction via Facebook, Twitter, and email: entertainment; brand engagement, specifically identification or connection with the brand; timeliness of information and service response; product information; and incentives and promotions; branded content; browsing; purchase; exclusivity; and trust. Ultimately, this literature can be used to understand what kind of strategies Coca-Cola and Calvin Klein might use within their campaign on Instagram to mobilize the audience to create content.

With the multitude of speculations regarding content production, free labour, and usergenerated content, critiques regarding the nature of the audience due to the interactive nature of the Internet come to light. The following review will address the role of the audience within social media.

\subsection{The Role of the Audience: From User to Producer to Advertiser}

Since this MRP will focus on the interactive nature of hashtag campaigns on Instagram, this review will address the shift of the "passive" audience to the proactive consumer. Throughout his works, Smythe (2010) maintained that content is sold to audiences, and in exchange sold to 
advertisers, which translates into the audience being both a product and a consumer. Due to the emergence of new modes of engagement on the Internet, Livingstone (2007) reexamines the term audience and concludes that such a term is no longer adequate as its description is only exclusive to activities pertaining to listening and watching. According to Livingstone (2007), a more appropriate term would be "user" which allows for more diverse modes of engagement, such as online shopping, online chatrooms, and video games. Napoli (2016) further develops this idea within the digital market where the relationship between consumer, advertisers and product is revolutionized as it invites new methods of engagements, which transforms the audience as producers of content. For instance, Instagram is a photo-sharing platform where users produce and share their own content. There have been instances where advertisers have used consumers to generate advertisements (Napoli, 2016). Platforms such as YouTube utilize and combine traditional media alongside user-generated content produced by "users", formally known as the "audience" (Napoli, 2016). In other words, YouTube utilizes users with a high number of subscribers and embeds mandatory commercial right before the commencement of that user's YouTube video (Napoli, 2016). Thus, social networking platforms, such as Instagram which serves as a multifaceted conversational framework, become great tools for advertisers and organizations. One of the hashtag campaigns that will be analyzed in this research paper is the \#ShareaCoke campaign, where consumers were invited to share a post whenever they were drinking or sharing a Coke product. Considering that the audience is acting as a producer of content for Coca-Cola, this research paper will seek to demonstrate how hashtag campaigns redefine the notion of free labour and the role of the audience from producer to advertisers of content. 
Further building on the foregoing, Fisher's (2014) research proposes that "the audience is involved in three moments along the value chain of social media: consumption, production and marketing" (p. 52). Taking in consideration the Coca-Cola campaign, the audience in social media is more than a commodity, they are in fact acting as media since they are constantly generating and maintaining their own communication channels by adverting their own content as well as the brand's (Fisher 2014). Fisher (2014) draws attention to users with a large social capital (number of followers), which he believes to be more significant than the communication generated by the audience sustained by “free labour". Fisher's work is relevant to this research paper as it will be analyzing the number of impressions and reach a brand obtains by employing its consumers to advertise its content via hashtag campaigns on Instagram. To be clear, impressions are the number of times a post from your page is displayed, whereas reach is the number of unique people who have seen that post (Facebook, 2017). Impressions are usually higher in number because a person can see multiple impressions of a post.

Fisher's (2014) notion in relation to the significance of users with a large social capital alludes to the concept of influencer marketing, specifically with the \#MyCalvins campaign which employed both celebrity endorsement and influencer marketing. Although celebrities can act as influencers, not all influencers are necessarily celebrities (Srinivasan, Srinivasa, \&Thulasidasan, 2013). In fact, influencers can also be defined as individuals with no prior fame who have accumulated a large following organically via social media (Influencers The New, 2006). The era of influencer marketing was shaped by two deciding factors, the first being the global economic downturn post 9/11 which resulted in a decline in sales and marketing budget cuts worldwide (Brown \& Hayes, 2008). The second event was the arrival of the web and the impact it had on the traditional marketing model as customers flocked online (Brown \& Hayes, 
2008). Anderson (2004) states that the digital era has diminished the trust in paid media used by organizations, and increased faith individuals (as sited in Brown \& Hayes, 2008). Subsequently, marketers have resulted to influencer marketing to get influential users to endorse a brand and influence others to do so (Brown \& Hayes, 2008). In other words, marketers are utilizing a digital word-of-mouth strategy via UGC to promote and market their product. However, Brown and Hayes (2008) identify issues with this strategy if influencers happen to be paid for their

UGC. In that case, they become paid brand ambassadors which damages the trust among consumers since the influencer now becomes a product of exploited marketing and loses their authenticity (Brown \& Hayes, 2008). Regarding the \#MyCalvins campaign, Calvin Klein used celebrity endorsement and paid its influencers to endorse their product, which, as per Brow and Hayes (2008), could damage the trust among consumers. However, the \#MyCalvins campaign proved to be successful and generated over 4.5 million interactions on Twitter alone (Leo, 2016). This literature can be used as a proposition to determine whether the \#MyCalvins campaign is still running a successful campaign despite Brown and Hayes' (2008) observations. This review can also help determine whether Coca-Cola's use of authentic user-generated content was more beneficial, thus, determining the extent "immaterial free labour".

\section{Research Questions}

The foregoing literature review has inspired the following research questions.

a. How does Smythe's (2006) work regarding free labour in relation to television and broadcast help understand social media today?

This will be the basis of my research and my main question. The goal of this research paper is to demonstrate how Smythe's theoretical framework regarding free labour 
regarding television and broadcast can be applied to users on social media. Smythe (2006) suggests that the audience is being sold to advertisers, and in exchange the audience performs free labour by watching for advertisers. However, with the emergence of the internet, advertisers have followed the audience to their latest platform. This research paper will seek to demonstrate that this phenomenon is still occurring on social networking websites, however the audience has shifted from user, to consumer, to producer, to advertiser. Thus, the term "free labour" has been revolutionized into various forms of "immaterial labour 2.0", as described by Pybus and Cote (2000).

\section{b. How do online brands, such as Coca-Cola and Calvin Klein, encourage or activate}

\section{the audience to participate in online campaigns?}

In order to answer the first question, the nature of hashtag campaigns must be defined. Smyth (2006) suggested that advertisers 'pay rent' to media companies with intention of accessing television audience (Yacoub, 2016). As a result, the audience performs a type of free labour by watching advertisers. However, advertising techniques have changed drastically due to the rise of social media. Therefore, this research question will focus on the different methods used by brands to entice the audience to participate in their campaign. As mentioned by Holt (2000) regarding postmodern brand management, a brand presents itself as "a cultural resource" to its consumers and then takes advantage of what consumers produce with such resource (Arvidsson, 2008). The goal of this research paper will be to analyze how hashtag campaigns produce culture by encouraging users to share content pertaining to the brand, to maximize the reach of the message and gain surplus value. This research will also seek to determine whether both campaigns 
employed the 10 motivations or themes that characterize brand-consumer interaction via social media as described by Rohm, et al. (2013). Ultimately, I will be analyzing two different brands which have employed different campaigns that differ in nature, such as celebrity-endorsed and influencer marketing campaigns (\#MyCalvins), as well as call-toaction campaigns (\#ShareaCoke). Although, these hashtags are different, this research paper will attempt to portray how they rely on UGC to advertise their brand which translates into a form of "immaterial labour" 2.0.

\section{c. Are all users supportive of the campaign?}

The purpose of this research question is to determine how users have responded to the campaigns. This research question will analyze the number of responses to determine its success. In this case, its success will be determined on whether users are performing a form of free labour by propagating and creating content for the brand. Thus, I will be focusing on whether the hashtag has been used correctly, and if the sentiment/nature of the post was positive or negative. This research question will also demonstrate the impact of the hashtag campaign and the multitudes of audiences they are obtaining. The goal is to determine whether the hashtag campaigns are in fact effective within the premise of Smythe's (2006) notion of free labour and audience commodity. The sentiment will be determined based on the elements retrieved from Question 2. And whether users imitated these elements in their posts. This research question will also highlight the difference in response between each respective campaign. 


\section{Data Collection Approach and Method of Analysis}

A mixed methods approach will be applied to this research paper through a qualitative content analysis of Instagram posts pertaining to both the brands and users, as well as quantitative data collection of these posts through an analytics software known as Keyhole. A more detailed explanation regarding the data collection approach and methods of analysis are further discussed throughout this section. Overall, this MRP will attempt to look at the implications of Smythe's (2006) work on free labour in broadcast television within a different perspective, the scope of Instagram. Thus, an inductive approach will be applied to this research paper. Questions 2-3 will gather both quantitative and qualitative data to answer the primary question, which relates to the theoretical framework of this MRP. Please note all data collected was obtained through public channels on Instagram, and therefore considered part of the public domain. Since manual data collection of hashtags on Instagram can prove to be quite lengthy, I will be employing the use of Keyhole which simply tracks and explores analytics for social media campaigns. Keyhole is a hashtag and keyword tracker. It allows the tracking of all posts in real time from Instagram or Twitter. Its real-time dashboard demonstrates the number of people who posted using the hashtag, along with the number of Likes and Impressions the campaign has generated. Keyhole will facilitate the examination of engagement and participation of users through the tracking of impressions and reach. The word "impression" implies the amount of views, and "reach" implies the amount of people. For example, if a post possesses 150 000 impressions and a reach of 50 000, that would imply that this post was viewed 150000 times 
among 50000 people. The following is a detailed analysis of what data will be collected and how it will be used to answer the research questions relating to this MRP

Question 1, “How does Smythe’s (2006) work regarding television and broadcast help us understand social media today", is the foundation of this MRP and will therefore be answered through a theoretical framework by applying Smythe's (2006) conclusions regarding free labour in television and broadcast to Instagram and social media. There will be no immediate data collection for this research question, however, the data collected from research questions and two and three will be employed to further explore the phenomenon of free labour within the context of social media and UGC. By analysing the nature of these campaigns in Question 2, "How do online brands encourage or activate the audience to participate in online campaigns", as well as the success of these campaigns in Question 3, "are all users supportive of the campaign", I will be able to determine whether these campaigns fit within context of digital marketing through user-generated content, thus, attempting to relate back to Smythe's (2006) concept of free labour and audience commodity.

Question 2, "How do online brands encourage or activate the audience to participate in online campaigns", will be answered through qualitative content analysis of the brand's Instagram posts. I will gather a systematic sample of posts and analyze a total of 100 posts for each brand within two separate timeframes: The beginning of the campaign and its present status. In other words, the very first 50 posts that originated after the launch of the campaign, along with the very last 50 posts the have been generated recently, will be subject to analysis. Thus, Coca-Cola's very first 50 Instagram posts were generated between June 30th, 2014 to October 30, 2014. Calvin Klein produced their very first 50 Instagram posts between February 18, 2014 to March 30, 2014. Thus, these will be the timelines subject to analysis. 
The second timeframe will focus on the latest 50 posts shared by each brand. The purpose of examining the very first 50 posts, in comparison to 50 of the most recent posts, is to determine whether the brand is consistent with its strategies, and whether the campaign is still active. It is important to note that this research is not inclusive to the posts regarding the hashtag campaign, but will focus on all the posts uploaded by the brand within that timeframe to determine the number of times they employ their own hashtag. For example, Calvin Klein uploads multiple posts that are not always relevant to the \#MyCalvins campaign.

The analysis of Instagram posts will be divided into two separate categories, such as visual and textual elements. Regarding the textual elements, captions, the use of hashtags, and personalized text will be observed to analyze content. The purpose of observing hashtags will determine the number of times the brand utilized their hashtag to promote their campaign; whether the brand used additional hashtags to maximize coverage and; whether the brand used an alternative hashtag irrelevant to the campaign. Differentiating between hashtags will demonstrate how many posts were dedicated to the campaign. The analysis will also look out for a "a call-to-action", and whether the brand interacts with its users. Visual elements will take in consideration the types of imagery, and whether they used people, celebrities, user-generated content, logo, or a product etc. The purpose of observing the elements used in each post will determine what online practices these campaigns use to encourage the audience to participate, and whether there is a common denominator for each campaign, such as user-generated curated content, and celebrity endorsements. Ultimately, this analysis will seek to determine how these brands communicate with their audience, and whether they employ the five primary motivations or themes that characterize brand-consumer interaction via social media such as entertainment, 
brand engagement, timeliness of information and service response, product information, as well as incentives and promotions (Rohm et al., 2013).

Furthermore, the analysis of visual and textual elements will also help determine whether users are mimicking the campaign and using the hashtag appropriately when performing the analysis in Question 3, "are all users supportive of the campaign?". The data will be manually inputted into an excel spreadsheet, divided into the three categories (caption, textual, visual) for each respective campaign. Observations will be noted for each post with the intentions of finding consistencies or differences. Again, the intentions of this analysis are to determine how a brand might encourage the audience to participate in the campaign by presenting itself as a "cultural resource" to its consumers, through online practices on Instagram (Arvidsson, 2008).

Regarding question 3, "are all users supportive of the campaign", two types of data collection will be employed. Initially, quantitative data collection will be conducted through Keyhole by tracking each one of the main hashtags (\#MyCalvins, \#Shareacoke) for a specific period. Due to limitations with Keyhole, data was only collected between the dates of July 8 , 2017 to July 11, 2017 for each campaign. Nonetheless, this timeframe corresponds to the timeframe available in "Question 2", which incorporates the brand's most recent posts. The intentions behind comparing the brand's most current content with recent user content is to determine a possible correlation, and if users are engaged with the brand although the campaigns are not recent. Throughout that time, Keyhole could provide the number of impressions (views) a hashtag has generated, and the reach (people) it has achieved. Keyhole also provides a graph that breaks down the number of posts users have contributed to the hashtag during the period sampled. The collection of such data will allow me to determine the multitude and success of the campaign in regard to the number of people it has reached. 
Furthermore, to establish whether users are supportive of the campaign, I will be conducting a binary sentiment analysis through systematic sampling. Keyhole organizes by date, all the posts generated by users who have utilized the hashtag. During the timeframe suggested above, I will be looking at a total of 50 user posts for each hashtag campaign. For each of the main hashtags, I will examine 50 of the most recent user posts between the timeframe mentioned above (July 8-July 11, 2017). Due to limitations with keyhole, historical data was unavailable for collection to compare the progression of the campaigns since their launch in 2014. However, the extent and success of each campaign has already been made aware throughout this text.

By analyzing the visual and textual elements of the post, I will determine the overall contextual nature of the content by classifying the post within three variables: positive (1), negative (2). The positive (1) variable corresponds to whether the user utilized the hashtag correctly; the negative (2) variable represents whether the user used the hashtag incorrectly, or whether the content had no relevance to the hashtag whatsoever. For example, Calvin Klein's \#MyCalvins focused mostly on the promotion of undergarments. However, if a user were to share a post regarding a different Calvin Klein product, this would be considered a negative use of the hashtag although the post relates to Calvin Klein. The same is applied to Coca-Cola. The purpose of this analysis is to determine whether users are mimicking the same elements that the campaigns has utilized. The binary sentiment analysis will be taken down, and tallied manually through an excel spreadsheet. Ultimately, the goal is to determine whether hashtag campaigns are an effective form of advertising in order to determine how Smythe's (2006) work can relate to social media today and Terranova's (2000) notion of immaterial labour. 


\section{Findings}

5.1) Question 2: "How do online brands encourage or activate the audience to participate in online campaigns?"

Regarding the qualitative content analysis performed on Coca-Cola's 50 first Instagram posts, $48 \%$ of the content had no relation to the \#ShareaCoke campaign. As mentioned previously, not all posts are inclusive to the campaign. However, within all posts examined the use of product, brand, colours, logo, user-generated content, people, humour, and video content were some of the elements observed within the posts. Furthermore, themes relating to sports, seasons, event, and holidays were also relevant within the Coca-Cola feed. The most prominent and consistent features within the visual factors were use of product $(92 \%)$, such as the iconic coke bottle; their famous red and white brand colours (44\%); people (36\%), their Coca-Cola logo (32\%); and user-generated content (30\%) (See Table 1.1). To be clear, user-generated refers to content generated by users for their respective feeds, which Coca-Cola then used to populate their own feed. Although a total of $30 \%$ of the content was user-generated among the 50 posts, $34.6 \%$ were user-generated amid the post relating to the \#ShareaCoke Campaign. The use of humour and sports can be classified as a motivation within the category of entertainment. All posts with a seasonal or event themes are considered to be "timely', which motivates users to participate. Lastly, all posts with user-generated content are considered as a form of brand engagement. All content posted was branded-content. Thus, Coca-Cola employed four of the ten motivational factors outlined by Rohm et al. (2013) within the 50 posts of their campaign.

Among the latest 50 posts from Coca-Cola, $68 \%$ had no relation to the \#ShareaCoke campaign, which indicates that the campaign is not as active as it was in 2014 . There has also been a drastic change in strategy. Although the use of product (92\%), logo (72\%), and people 
(48\%) were among the most prominent visual elements, user-generated content $(2 \%)$ which consisted of $30 \%$ of posts in 2014 is now almost non-existent (See Table 1.2).

Within the textual elements observed among the first 50 posts launching the campaign, the use of personalized text (58\%), hashtag (46\%), and alternative hashtag (38\%) were the most frequently used textual elements. As mentioned previously, the use of hashtag indicates promotion of the campaign, an alternative hashtag represents posts irrelevant to the campaign such as \#CocaColaSummerRecipes, \#LastSipsOfSummer, \#Tiny Coke, etc. In this case, CocaCola seemed to have dedicated a little less than half of its posts to the campaign. Regarding personalized text, this reflects all the posts that Coca-Cola used to address its users by mentioning their usernames within their caption (See Figure 1.3) Personalized text also indicates all the posts where personal names were mentioned or listed on the coke bottles in the images shared online. These textual elements correspond ideally with the \#shareacoke campaign considering Coca-Cola's goal was to personalize their brand with its consumers. Personalized posts can be seen a form of brand engagement. Furthermore, UGC content featured on CocaCola's feed can act as an incentive for other users to generate content who might want to be featured as well. To further personalize their posts, Coca-Cola used holiday themed (6\%), and event themed $(6 \%)$ visual elements in order to be more relatable among its audience in a timely manner.

Regarding the most recent 50 \#ShareaCoke posts, the use of alternative hashtags $(56 \%)$, hashtag (32\%), and emoji (32\%) were the most popular. Many posts employed alternative hashtags, such as \#NationalPuppyDay, \#NationalGrilledCheeseDay, \#ChineseNewYear, etc. This indicates that the brand is still attempting to be relatable, timely and personable among its consumers, but not necessarily directly via the \#ShareaCoke hashtag. Nonetheless, $32 \%$ of posts 
corresponded to the \#Shareacoke campaign which indicates the campaign is still active but not as prominent as before. Furthermore, since the brand rarely utilized any user-generated content, there was little use of personalized text and user mentions (3\%) in comparison to the launch of the campaign. In addition, only $10 \%$ of posts used a call-to-action - however, among those $10 \%$, only $2 \%$ was in relation to the \#ShareaCoke campaign.

With regards to the Calvin Klein Instagram account, fifty of the firsts posts marking the campaign debut were analysed for data. Again, not all fifty posts were relevant to the \#MyCalvins campaign. In fact, among the fifty, $52 \%$ were related to the \#MyCalvins campaign. The most prominent use of visual elements among all posts was the presence of a product (86\%), particularly Calvin Klein underwear. Among the $86 \%, 64 \%$ included a celebrity wearing the product. $42 \%$ included user-generated content, however a clear majority of this content was generated by celebrities or influencers. In fact, among the posts exclusive to the \#MyCalvins Campaign (52\%), 69\% was celebrity endorsed content. Furthermore, a reoccurring theme present in $38 \%$ of the posts was seduction which represents the nature of the \#MyCalvins campaign. In regards to the most recent 50 \#MyCalvins posts, the use of product (66\%), Celebrities (38\%), Celebrities wearing products (38\%) were still among the most popular visual elements utilized. Only $20 \%$ of posts had a seductive nature, which has decreased since the launch, thus, possibly demonstrating a potential change in branding.

Regarding textual elements, the earlier posts contained a celebrity mention (39\%), product mention (27\%), the \#MyCalvins hashtag (24\%), an alternative hashtag (24\%), an additional hashtag (22\%), and a call-to-action (4\%). In this case, $40 \%$ of the additional hashtags referred to the \#regram hashtag which indicates the use of user-generated content. Within the Instagram culture, \#regram refers to the act of reposting content that has primarily originated elsewhere. In 
other words, "regram" can be translated into "repost". In this case, the \#regram was used on celebrity endorsed posts, which signifies that celebrities originally uploaded content relative to Calvin Klein on their personal feeds, which then subsequently resulted as a "repost" by Calvin Klein on their respective feed. Ultimately, the constant use of the \#regram indicates the heavy reliance on user-generated content and celebrity endorsements which have fuelled the campaign. In relation to the most recent posts, there is a significant change in technique. Although celebrity mention (39\%), product mention (32\%), and alternative hashtag (20\%) are still among the most prominent textual elements, there is very little use of the \#MyCalvins hashtag (6\%), and absolutely no use of an additional hashtag, which indicates no use of the \#regram, and thus zero use of celebrity endorsed user-generated content as presented earlier.

Overall, the \#MyCalvins campaign presents itself as form of brand engagement, allowing users to potentially identify with the brand as well as the celebrities/influencers promoting the brand. This notion could also be translated into a form of incentive. The same could be said about the \#ShareaCoke campaign despite the lack of celebrity endorsement and influencer marketing. Based on the 10 motivations highlighted Rohm et al. (2013), both campaigns used brand engagement, branded content, and product information as motivations to generate consumer-brand engagement.

5.2 Question 3, “Are all users supportive of the campaign?”

As mentioned, due to limitations with Keyhole, data was only collected within a limited timeframe. Regarding the \#ShareaCoke campaign, quantitative data collection was performed by tracking the hashtags between July 8, 2017 to July 12, 2017. Within four days, 653 posts using the \#Shareacoke hashtag were generated among 600 users. The posts reached over 100,000 users (reach), and was viewed over a 100,000 times (impressions) (See Figure 2.1). The exact number 
was unavailable due to service limitations with Keyhole. In relation to the \#MyCalvins campaign, the timeframe observed was between July 8, 2017 and July 11, 2017—- a day less than the \#ShareaCoke Campaign. The hashtag was employed in 639 posts among 528 users. These posts also reached over 100,000 users (reach) and was viewed over 100,000 times (impressions) among those users (See Figure 2.2). This demonstrates that the \#MyCalvins obtained just as much traffic and engagement as the \#ShareaCoke Campaign within a smaller timeframe.

Regarding the binary sentiment analysis, the results are as follows. Among 50 of the latest \#Shareacoke user-generated posts examined on July 11, 2017, 84\% were positive (1), and 16\% were negative (2) (See Table 3.1). For a post to be considered positive, the content must include the product, and/or users consuming the product. For instance, one user posted a photo of the product and which displayed his name, and then invited his followers to go and do the same (See Figure 1.4). Any absence of product, or relation to the brand, qualifies as a negative post. However, in one instance, one user did portray the product and addressed the brand, but criticized Coca-Cola in terms of health concerns stating that the product is a known corrosion inhibitor which can damage the stomach (See Figure 1.5). On another occasion, one user uploaded a photo relating to Coca-Cola, but not the campaign. In this case, such content would be considered negative use of the hashtag campaign, but positive advertising of the brand. Overall, majority of users seem to be using the hashtag correctly, and seem to be mimicking the \#ShareaCoke feed through use of product.

Moreover, among 50 of the latest \#MyCalvins user-generated posts on July 11, 2017, 72\% were positive (1), and 28\% were negative (2) (See Table 3.1) To be considered positive, the post must display the product, the product must be Calvin Klein underwear, the user must be wearing the 
product (See Figure 1.6). In figure 1.6, the user accumulated over 300 likes on their photo, which demonstrates the amounts of people it reached, despite this user being not an influencer.

On one occasion, a user mentioned purchasing a Calvin Klein watch in his caption, but did not display a photo of the product. In this case, the post would be considered negative since it has no relation to the Calvin Klein underwear.

\section{Conclusions}

The dataset collected was able to fully answer the research in question. This MRP set out to determine how Smythe's (2006) work regarding free labour regarding television and broadcast help understand social media today, particularly Instagram and the effect of hashtag campaigns. To determine the relationship between Smythe's (2006) work and social media, the \#MyCalvins and \#ShareaCoke campaigns were analyzed to broaden the understanding of the online practices which they've adopted to mobilize the audience. The findings derived from the second research question, "how do online brands activate the audience to participate in online campaigns", demonstrate that both campaigns have utilized different strategies but their intent to influence the creation of user-generated content among consumers is parallel. The findings demonstrated that the primary goal of these campaigns was to mobilize the audience in creating and sharing content. Coca-Cola insisted on users "sharing a coke", both virtually and physically, while Calvin Klein invited users to "show their Calvins". This notion relates to Smythe's (2006) work regarding audience commodity, where the audience has become a product for the commercial mass media. In this case, considering the reach and amount of impressions generated by users in question 3, Coca-Cola and Calvin Klein benefit from reaching the audience, and in return encourages the access of more audiences, which renders them a commodity (Smythe 2010; Fuchs, 2012). The ways in which advertisers can access the audience has changed drastically 
since Smythe's (2006) work on television broadcast. However, no useful medium ever disappears, only the technology and protocols for how content is delivered change (McStay, 2010). Rather than paying "rent" to media/broadcasting companies to access the audience, as mentioned by Smythe (2006), brands entice users to participate in their campaign by generating more content through the implementation of the hashtag in hopes of accessing more audience. Brands still use a medium (Instagram) to propagate their campaign, but are no longer required to pay to access the audience considering the infrastructure and nature of the "participative web". Based on the findings and Laestadius and Wahl's (2017) research, these campaigns relied on consumers' desire of creating UGC with the hopes of contributing to a creative process and engaging in self-expression, or gaining some form celebrity status or prestige. Coca-Cola featured UGC on their feeds as incentive to get other users involved and want to be featured as well. On the other hand, Calvin Klein utilized influencers to influence users into wanting to achieve the same prestige as the celebrities endorsing the brand. These campaigns, particularly highlight the way in which information is delivered and how the audience is accessed. By enticing users to participate in their campaign by generating content, the audience now becomes producers of content via UGC (Livingstone, 2007; Napoli, 2016). As producers of content, they consequently perform a type of free labour by producing value via the information they share with their social networks (Andrejevic, 2002; Terranova, 2007). These observations suggest that users are performing a form of free labour as described by Smythe (2006), however, there are differences in how labour is commodified. The labour performed by the audience/user is still free, but has however changed in nature. Instead of working for free by watching, the audience is working for by consuming, producing, and advertising content. In this case, users are creating and advertising content for Coca-Cola and Calvin without any sort of compensation other than 
involvement in the campaign. In fact, the data collected from question 3 suggests that users are still producing despite the brands, particularly Calvin Klein, no longer advertising the hashtag campaign. Thus, it appears users are advertising the brand on their own, and thus, are inadvertently working as advertisers for the brand, which amounts to a form of modern free labour. The brand no longer needs to promote the hashtag in order to reach consumers, because consumers are being employed to reach other consumers, which makes both UGC content and users commodities. Although Calvin Klein paid its influencers to create content, the remainder the vast user population performed free labour. Ultimately, brands benefit from free advertising and revenue as a result of such advertising.

Furthermore, users are creating content for both brands and Instagram as well. As mentioned by Fuchs (2010), social networking websites such as Facebook depend on content to survive as an entity since it exclusively hosts and fosters UGC. Considering Instagram is a photo sharing website, and an active entity of the "participative web", Fuchs (2010) observations apply in such a situation. Therefore, UGC is essential to Instagram. That being said, users are sustaining the digital economy. According to Fuchs (2012), these practices are exploiting users since there is no legitimate compensation for the data they provide. Having mere access to a communication service is not a method of survival and therefore cannot be considered a legitimate wage since "the relationship between users and platforms [is not] organized in the form of a modern wage relationship" (Fuchs, 2012, p. 703). Fuchs' (2012) notions can be applied to hashtag campaigns which advertise creative expression and brand involvement in exchange for UGC. UGC is an activity that produces value and can be monetized for brands, however, users producing UGC do not gain the same benefits. 
This notion alludes to Terranova's (2000) concept of "immaterial labour", where usergenerated content builds culture for the digital economy. As defined by Lazzarato (1996), culture is cultural conventions, etiquette of fashion, consumer behaviour, and public opinion--- all factors which helped shape and continue shaping the hashtag campaigns. In other words, Terranova (2007) implies that the act of producing content online corresponds to Smythe's (2006) notion of free labour, where users are working for free by producing and absorbing content. However, the content produced is immaterial, such as building websites and virtual spaces with content. Nonetheless, this content is sustaining the digital economy. Essentially, Smythe (2006) and Terranova (2007) describe the same concept, but differ in how free labour is commodified.

To conclude, Smythe's (2006) observations regarding audience commodity and free labour are still present in today's digital age, but are manifested differently due to the nature of the interactive web. The nature of the audience has shifted from user, to producer, and advertiser of content (Livingstone, 2007; Napoli 2016). There is no official method explaining how brands mobilize the audience to act as producers and advertisers of content—however, Holt (2000) suggested that a brand presents itself as a "cultural resource" to its consumers and takes advantage of what consumers produce with such a resource. In this case, the hashtag is considered a form of brand engagement, presenting itself as a cultural resource promising consumers a type of involvement in the campaign. That being said, if users are creating content as culture defined by Terranova (2000), and hashtag presents itself as a cultural resource, therefore, hashtags become a resource for user content, which could potentially explain their popularity and success in campaigns. 


\section{Appendix A: Data sources}

Table 1.1: Initial 50 \#ShareaCoke Posts

\section{Content Analysis Statistics}

\begin{tabular}{|c|c|c|}
\hline Themes & $\begin{array}{c}\text { Number of } \\
\text { posts/50 }\end{array}$ & Percentage \\
\hline \multicolumn{3}{|l|}{ Visual } \\
\hline Product & 46 & $92 \%$ \\
\hline Brand colours & 22 & $44 \%$ \\
\hline People & 18 & $36 \%$ \\
\hline Logo & 16 & $32 \%$ \\
\hline $\begin{array}{c}\text { User-generated } \\
\text { Content }\end{array}$ & 15 & $30 \%$ \\
\hline People & 14 & $28 \%$ \\
\hline Humour & 8 & $16 \%$ \\
\hline Video & 7 & $14 \%$ \\
\hline Holiday themed & 6 & $12 \%$ \\
\hline Event themed & 3 & $6 \%$ \\
\hline Season themed & 3 & $6 \%$ \\
\hline Sports themed & 3 & $6 \%$ \\
\hline \multicolumn{3}{|l|}{ Textual } \\
\hline Personalized text & 29 & $58 \%$ \\
\hline Hashtag & 23 & $46 \%$ \\
\hline Alternative hashtag & 19 & $38 \%$ \\
\hline Humour & 12 & $24 \%$ \\
\hline Additional Hashtag & 9 & $18 \%$ \\
\hline Call-to-action & 9 & $18 \%$ \\
\hline Question & 9 & $18 \%$ \\
\hline
\end{tabular}

Table 1.2: Latest 50 \#ShareaCoke Content Analysis Statistics

\begin{tabular}{|c|c|c|}
\hline Themes & $\begin{array}{c}\text { Number of } \\
\text { posts } / 50\end{array}$ & Percentage \\
\hline \multicolumn{3}{|l|}{ Visual } \\
\hline Product & 46 & $92 \%$ \\
\hline Logo & 36 & $72 \%$ \\
\hline People & 24 & $48 \%$ \\
\hline Holiday themed & 23 & $46 \%$ \\
\hline GIF & 16 & $32 \%$ \\
\hline Event themed & 9 & $18 \%$ \\
\hline Brand colours & 7 & $14 \%$ \\
\hline Video & 4 & $8 \%$ \\
\hline Season themed & 3 & $6 \%$ \\
\hline Humour & 3 & $6 \%$ \\
\hline Sports themed & 2 & $4 \%$ \\
\hline Pop Culture & 1 & $2 \%$ \\
\hline $\begin{array}{c}\text { User-generated } \\
\text { Content }\end{array}$ & 1 & $2 \%$ \\
\hline \multicolumn{3}{|l|}{ Textual } \\
\hline Alternative hashtag & 28 & $56 \%$ \\
\hline Hashtag & 16 & $32 \%$ \\
\hline Emoji & 16 & $32 \%$ \\
\hline Additional Hashtag & 6 & $12 \%$ \\
\hline Call-to-action & 5 & $10 \%$ \\
\hline Question & 5 & $10 \%$ \\
\hline Pop Culture & 5 & $10 \%$ \\
\hline Personalized text & 3 & $6 \%$ \\
\hline Humour & 1 & $2 \%$ \\
\hline
\end{tabular}


Table 2.1: Initial 50 \#MyCalvins Posts

Content Analysis Statistics

\begin{tabular}{|c|c|c|}
\hline Themes & $\begin{array}{l}\text { Number of } \\
\text { posts } / 50\end{array}$ & Percentage \\
\hline \multicolumn{3}{|l|}{ Visual } \\
\hline Product & 43 & $86 \%$ \\
\hline $\begin{array}{l}\text { Celebrity wearing } \\
\text { product }\end{array}$ & 32 & $64 \%$ \\
\hline $\begin{array}{l}\text { User-generated } \\
\text { content }\end{array}$ & 21 & $42 \%$ \\
\hline Seductive & 19 & $38 \%$ \\
\hline Celebrity & 6 & $12 \%$ \\
\hline $\begin{array}{l}\text { Models wearing } \\
\text { product }\end{array}$ & 2 & $4 \%$ \\
\hline $\begin{array}{l}\text { Image of news } \\
\text { publication }\end{array}$ & 1 & $2 \%$ \\
\hline Video & 1 & $2 \%$ \\
\hline \multicolumn{3}{|l|}{ Textual } \\
\hline Celebrity mention & 39 & $78 \%$ \\
\hline Product mention & 27 & $54 \%$ \\
\hline Alternative hashtag & 24 & $48 \%$ \\
\hline Hashtag & 24 & $48 \%$ \\
\hline Additional Hashtag & 22 & $44 \%$ \\
\hline Call-to-action & 4 & $8 \%$ \\
\hline
\end{tabular}

Table 2.1: Latest 50 \#MyCalvins Posts

Content Analysis Statistics

\begin{tabular}{|c|c|c|}
\hline Themes & Number of posts/50 & Percentage \\
\hline \multicolumn{3}{|l|}{ Visual } \\
\hline Product & 33 & $66 \%$ \\
\hline $\begin{array}{l}\text { Celebrity wearing } \\
\text { product }\end{array}$ & 19 & $38 \%$ \\
\hline Celebrity & 19 & $38 \%$ \\
\hline Seductive & 10 & $20 \%$ \\
\hline Video & 8 & $16 \%$ \\
\hline $\begin{array}{c}\text { Models wearing } \\
\text { product }\end{array}$ & 5 & $10 \%$ \\
\hline $\begin{array}{c}\text { Image of news } \\
\text { publication }\end{array}$ & 4 & $8 \%$ \\
\hline $\begin{array}{c}\text { Sharing of personal } \\
\text { story }\end{array}$ & 3 & $6 \%$ \\
\hline User-generated content & 0 & $0 \%$ \\
\hline \multicolumn{3}{|l|}{ Textual } \\
\hline Celebrity mention & 39 & $78 \%$ \\
\hline Product mention & 32 & $64 \%$ \\
\hline Alternative hashtag & 20 & $40 \%$ \\
\hline Hashtag & 3 & $6 \%$ \\
\hline Additional Hashtag & 0 & $0 \%$ \\
\hline Call-to-action & 0 & $0 \%$ \\
\hline
\end{tabular}


Table 3.1: Binary Sentiment Analysis

of \#ShareaCoke and \#MyCalvins User Posts

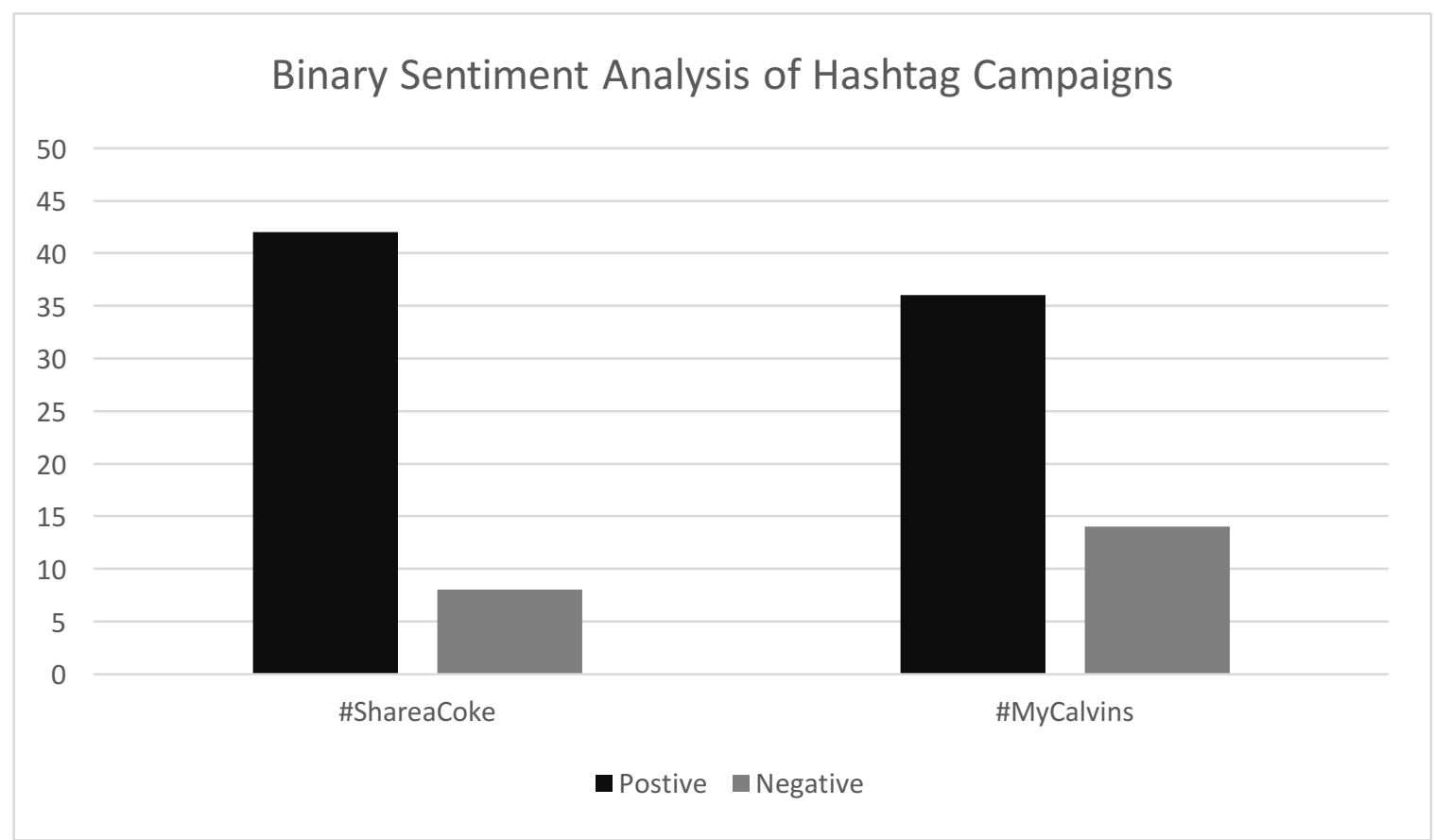




\section{Appendix B: Figures}

Figure 1.1: Share a Coke Campaign packaging
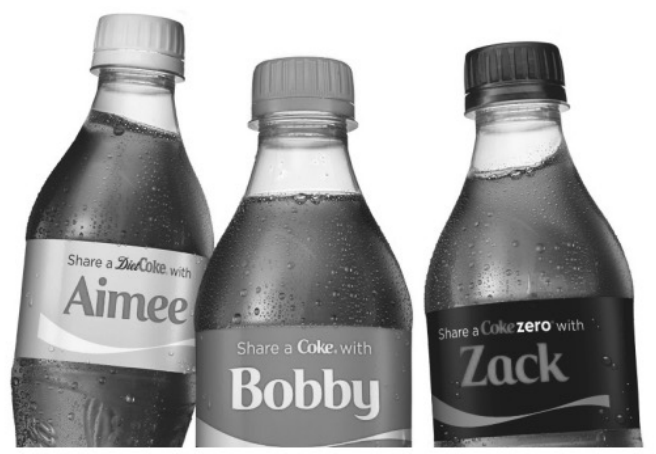

Figure 1.2: \#MyCalvins initial campaign launch

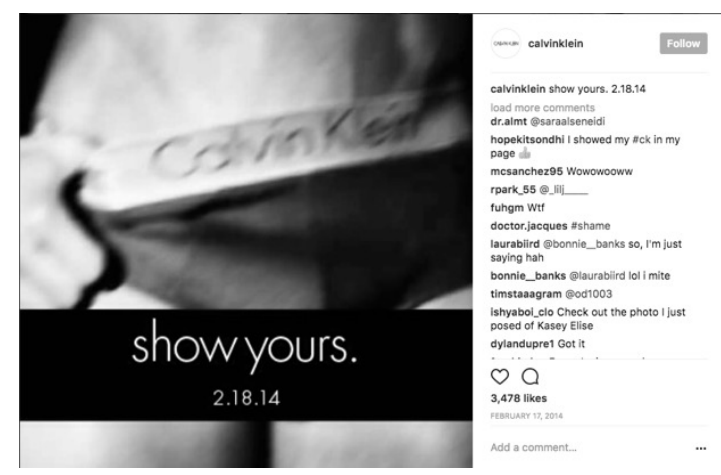

Figure 1.3: Coca-Cola personalizing campaign through UGC and user mention

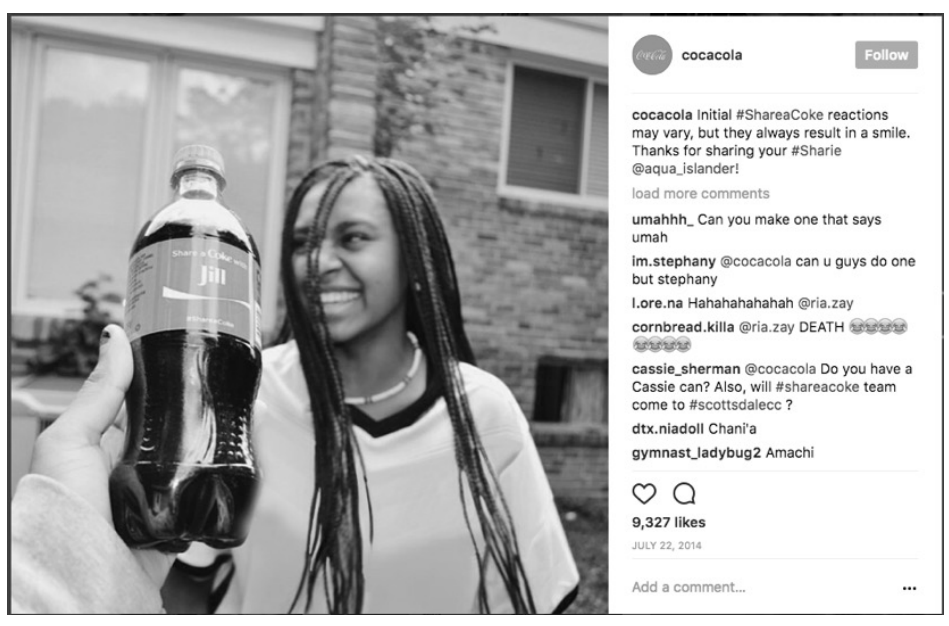


Figure 1.4: User-Generated Content For \#ShareaCoke

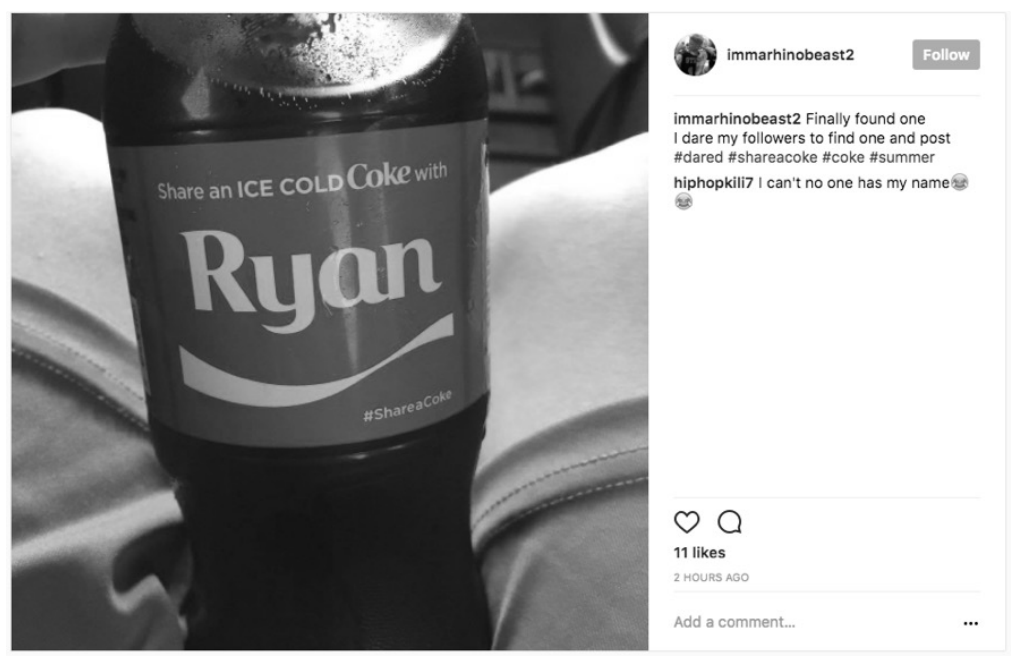

Figure 1.5: Negative use of User-Generated Content for \#ShareaCoke
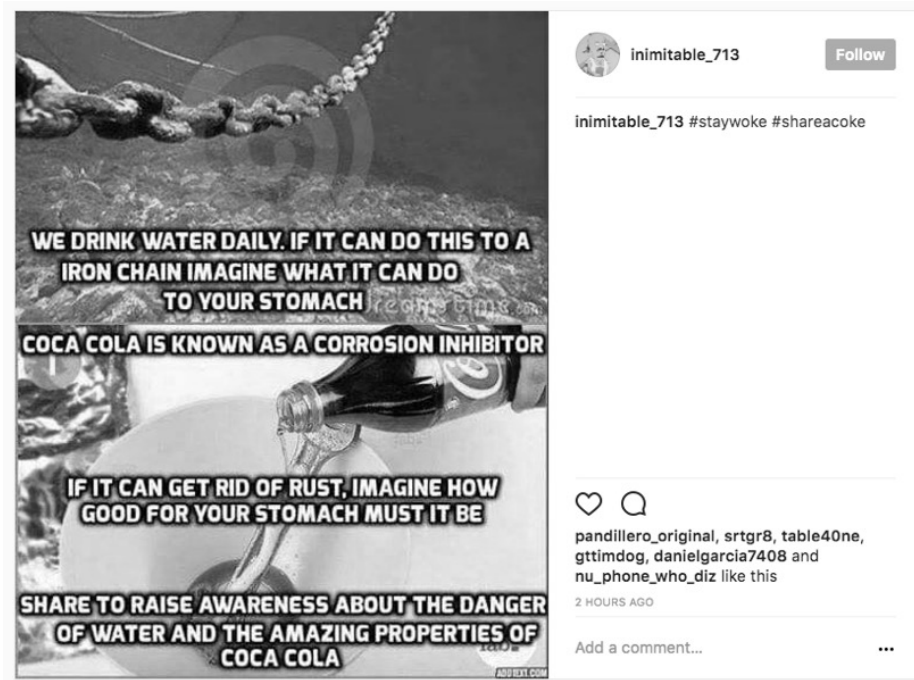
Figure 1.6: \#MyCalvins User-Generated Content

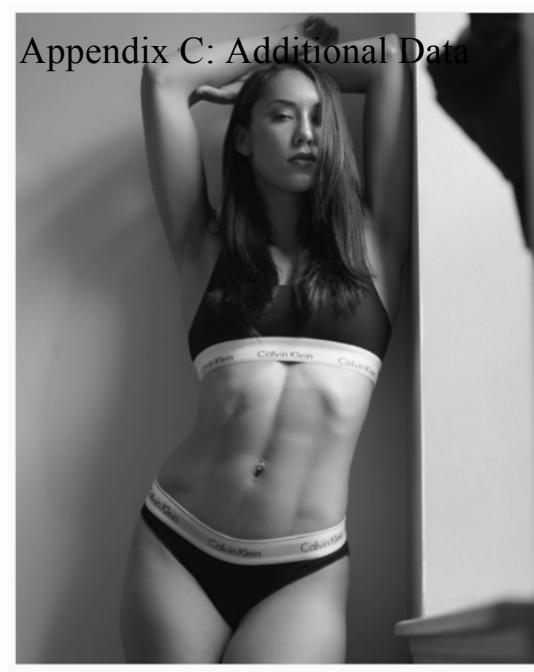

\begin{tabular}{|c|c|}
\hline $\begin{array}{l}\text { jasminee } \\
\text { New York }\end{array}$ & Follow \\
\hline \multicolumn{2}{|c|}{$\begin{array}{l}\text { jasmineennabe Just hanging around in } \\
\text { \#mycalvins @-@fstopkiller7 }\end{array}$} \\
\hline \multicolumn{2}{|c|}{$\begin{array}{l}\text { jasmineennabe \#portraitsociety } \\
\text { \#portraitpage \#makeportrait } \\
\text { \#makeportraits \#portrait \#model } \\
\text { \#portraitvvision \#portraitgames } \\
\text { \#dynamicportraits \#discoverportrait } \\
\text { "postthepeople \#portraitmood } \\
\text { \#agameofportraits \#nycrimeshot } \\
\text { \#nycprime_ladies \#portraits_vision } \\
\text { \#dreamdwellers \#calvinklein \#mycalvins }\end{array}$} \\
\hline \multicolumn{2}{|c|}{ rjmediaconsulting Gorgeous } \\
\hline \multicolumn{2}{|c|}{ hisnameiscourtney 666} \\
\hline \multicolumn{2}{|c|}{ shotbycv Fireeeeeeee } \\
\hline \multicolumn{2}{|l|}{ whcoles Wow wow } \\
\hline \multicolumn{2}{|c|}{ peterjacobb Yessss! } \\
\hline \multicolumn{2}{|l|}{ 4estttt } \\
\hline \multirow{2}{*}{\multicolumn{2}{|c|}{$0 \bigcirc$}} \\
\hline & \\
\hline \multicolumn{2}{|l|}{307 likes } \\
\hline 2 DAYSAGO & \\
\hline
\end{tabular}

\section{Appendix C: Additional Data}

Figure 2.1: \#ShareaCoke Impressions and Reach

\section{Real-time Tracker: shareacoke}

$\underset{\text { Posts }}{683}$

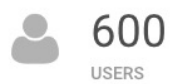

USERS
HISTORICAL DATA

JUL 8 - JUL $12 \quad \checkmark$

$\downarrow$ PDF

$\downarrow \mathrm{XLS}$

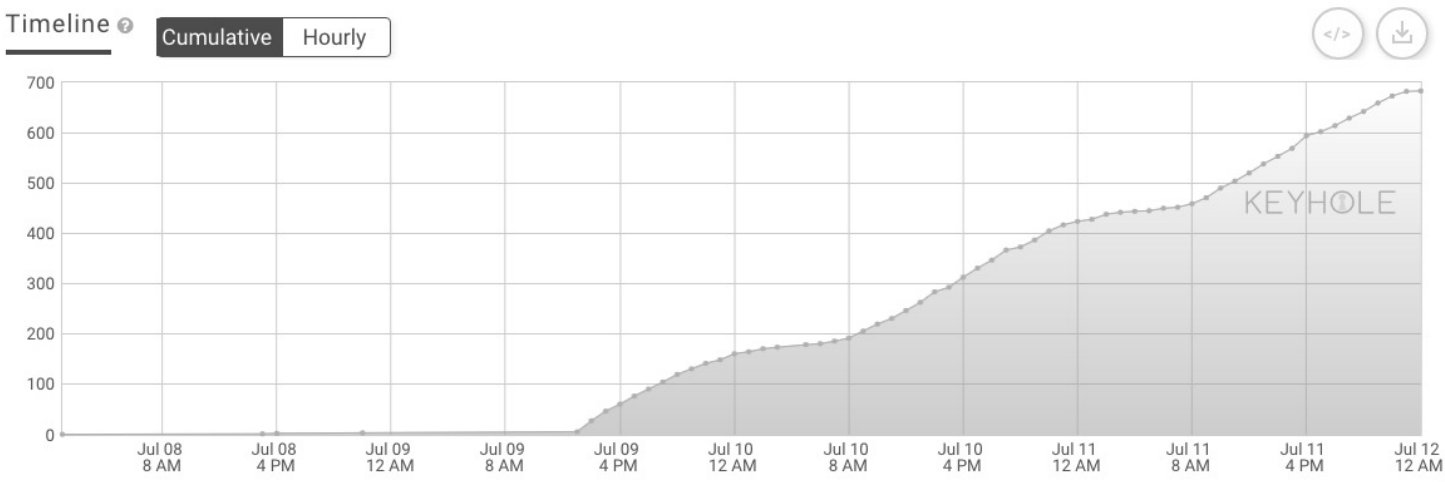


Figure 2.2: \#ShareaCoke Impressions and Reach

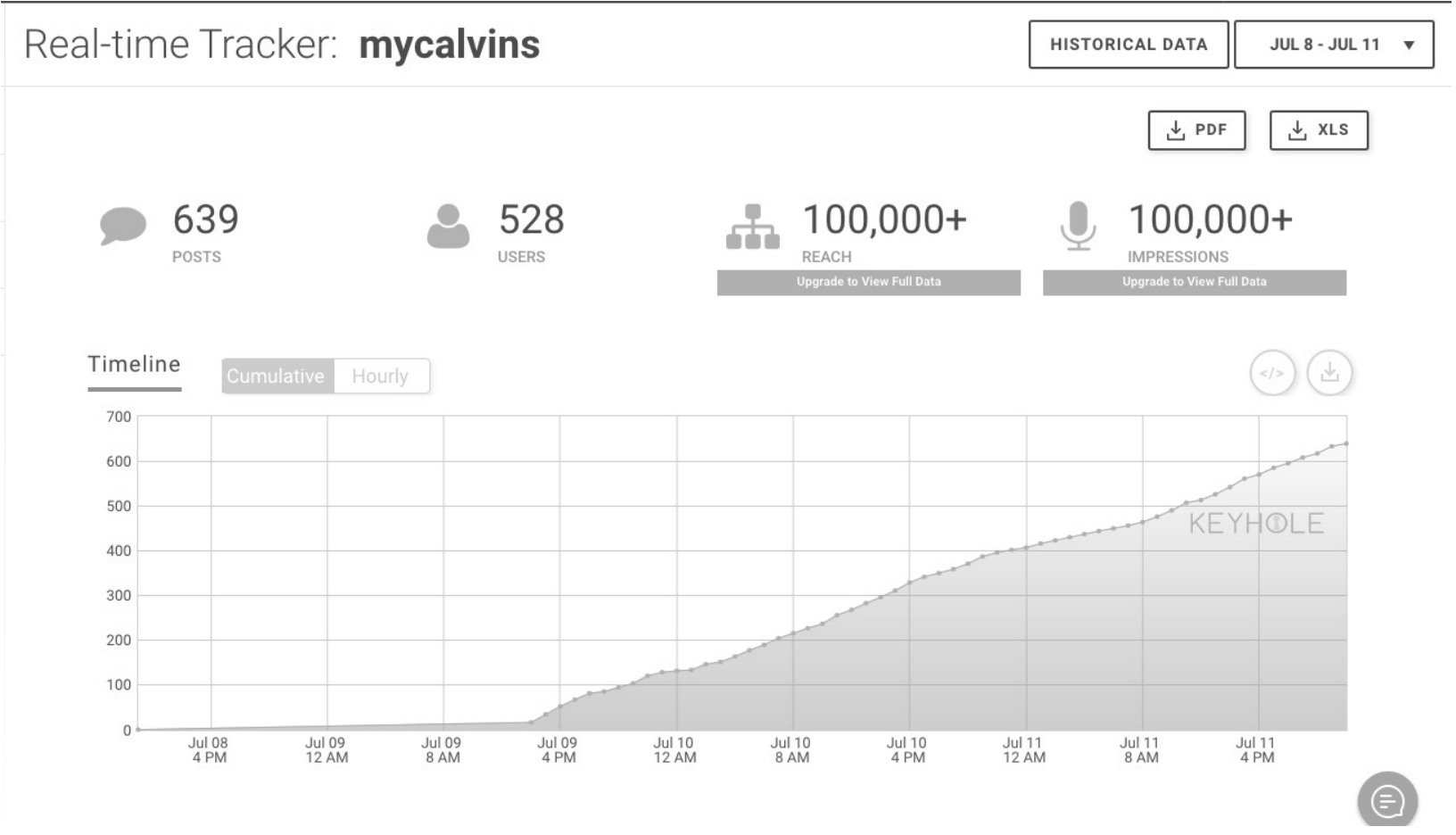




\section{References}

Andrejevic, M. (2002) The work of being watched: interactive media and the exploitation of selfdisclosure, Critical Studies in Media Communication, 19(2), 230-248, doi:10.1080/07393180216561

Arvidsson, A. (2005). Brands: A critical perspective. Journal of Consumer Culture, 5(2), 235258. DOI:10.1177/1469540505053093

Brown, D., \& Hayes, N. (2008). Influencer marketing: who really influences your customers? Oxford: Elsevier.

Coté, M., \& Pybus, J. (2007). Learning to immaterial labour 2.0: Myspace and social networks. Ephemera, 7(1), pp. 88-106. SSN 1473-2866

Dal, Y.J., \& Feenberg, A. (2015) Commodity and Community in Social Networking: Marx and the Monetization of User-Generated Content, The Information Society, 31(1), 52-60, doi: $10.1080 / 01972243.2015 .97763$

Drury, G. (2008). Opinion piece: Social media: Should marketers engage and how can it be done effectively? Journal of Direct Data and Digital Marketing Practice, 9(3), 274-277. doi:10.1057/palgrave.dddmp.4350096

Facebook Help Centre: What's the difference between impressions and reach? (n.d.). Retrieved February 06, 2017, from https://www.facebook.com/help/274400362581037?helpref=uf_permalink

Fisher, E. (2014). 'You Media': Audiencing as marketing in social media. Media, Culture \& Society, 37(1), 50-67 doi:10.1177/0163443714549088

Fuchs, C. (2012). Dallas Smythe Today - The Audience Commodity, the Digital Labour Debate, Marxist Political Economy and Critical Theory. Prolegomena to a Digital Labour Theory 
of Value. Triple C: Communication, Capitalism \& Critique. Open Access Journal for a Global Sustainable Information Society. Retrieved October 03, 2016, from http://www.triple-c.at/index.php/tripleC/article/view/443

Hepburn, M. (n.d.). Share a Coke [Web log post]. Retrieved from http://www.cocacola.co.uk/stories/share-a-coke

Influencers The New. (2016). PR Week, 29. Retrieved from http://ezproxy.lib.ryerson.ca/login?url=https://search-proquestcom.ezproxy.lib.ryerson.ca/docview/1818709094?accountid=13631

Jhally, S., \& Livant, B. (1986). Watching as Working: The Valorization of Audience Consciousness. Communication Journal of Communication, 36(3), 124-143. doi: 10.1111/j.1460-2466.1986.tb01442.x

Laestadius, L. I., \& Wahl, M. M. (2017). Mobilizing social media users to become advertisers: Corporate hashtag campaigns as a public health concern. Digital Health, 3, 205520761771080. doi:10.1177/2055207617710802

Lazzarato, M. (1996). Immaterial labor. Radical thought in Italy: A potential politics, 1996, 13347

Leo, S. (2016, February 03). \#MyCalvins campaign takes over the internet. Retrieved July 23, 2017, from http://www.trulydeeply.com.au/2016/02/mycalvins-viral-campaignadvertising-brand 
Livingstone, S. (2007). The Changing Nature of Audiences: From the Mass Audience to the Interactive Media User. A Companion to Media Studies, 337-359. doi:10.1002/9780470999066.ch17.

McStay, A. (2010). Digital Advertising . London, EN: Palgrave Macmillan. doi:https://books.google.ca/books?id=mOEcBQAAQBAJ\&printsec=frontcover\#v=onepa ge\&q\&f=false

Napoli, P. M. (2016). The Audience as Product, Consumer, and Producer in the Contemporary Media Marketplace. Managing Media Firms and Industries, 261-275. doi:10.1007/978-3319-08515-9_15

OECD (2007), Participative Web and User-Created Content: Web 2.0, Wikis and Social Networking, OECD Publishing, Paris. http://dx.doi.org/10.1787/9789264037472-en

Rohm, A., Kaltcheva, D.V., \& Milne, R.G. (2013). A mixed-method approach to examining brand-consumer interactions driven by social media. Journal of Research in Interactive Marketing, 7(4), 295-311.

Serazio, M. (2015) Selling (digital) Millennials The Social Construction and Technological Bias of a Consumer Generation. Television \& New Media; 599-615.

Srinivasan, M. S., Srinivasa, S., \& Thulasidasan, S. (2013). Exploring celebrity dynamics on Twitter. Proceedings of the 5th IBM Collaborative Academia Research Exchange Workshop on - I-CARE 13. doi:10.1145/2528228.2528242

Smythe, Dallas. (2006) On the Audience Commodity and It's Work. Media and Cultural Studies:Keyworks. Blackwell Publishing. 230-47. Google Books. Web. 01 Oct. 2016. 
Terranova, T. (2000) Free Labor: Producing culture for the digital economy. Social Text, 18(2) 63: 33-58. Web. 